\title{
Estrategias de codificación de información empleadas por docentes Mexicanos en procesos de formación
}

\section{Information coding strategies employed by Mexican teachers in training processes}

\author{
Flavio Ortega Muñoz \\ Miguel Ángel Muñoz López \\ David Vázquez Valenzuela \\ Diana María Espinosa Sánchez \\ Centro de Actualización del Magisterio de Durango, México
}

Autor para correspondencia: flavioaguilucho@hotmail.com, miguelarcangel@comunidad.unam.mx,dav_vz_v@hotmail.com,dianaespin@hotmail.com Fecha de recepción: 02 de Agosto de 2017 - Fecha de aceptación: 30 de Septiembre de 2017

Resumen: Las Estrategias de Codificación de Información refieren al conjunto de procedimientos que conectan los conocimientos previos, integrándolos en estructuras de significado más amplias y transportándolos a la memoria de largo plazo (Pizano, 2012). En el presente estudio se planteó como objetivo general establecer un perfil descriptivo que contemple las Estrategias de Codificación de Información que emplean los Docentes que estudian el Posgrado en el Centro de Actualización del Magisterio (CAM). En una segunda etapa, se ampliará dicho perfil con base en los resultados obtenidos con otros estudiantes que cursan distintos programas en el resto de las Instituciones Formadoras de Docentes en el estado de Durango, México. Para el logro del objetivo citado, se realizó un estudio exploratorio, descriptivo-correlacional, transversal y no experimental. La recolección de información se efectuó mediante la Escala de Estrategias de Aprendizaje ACRA, que fue aplicada a 67 estudiantes que durante el mes de octubre de 2016 cursaban la Maestría en Educación, Campo Intervención Didáctica (MECID), en alguna sede del CAM. Los principales resultados obtenidos muestran que los encuestados presentan un nivel medio de frecuencia de empleo de Estrategias de Codificación de Información (66\%) y que la variable Género tiene un efecto modulador.

Palabras claves: estrategias de aprendizaje; estrategias de codificación de información; docentes; procesos de formación

Abstract: The Information Coding Strategies are the cluster of procedures that connect previous knowledge with new data, integrating them into broader meaning structures and transporting them to long-term memory (Pizano, 2012). In this research, the general objective is to establish a descriptive profile that contemplates the Information Coding Strategies that the Teachers who study the postgraduate at Centro de Actualización del Magisterio (CAM) use. In a second stage, the profile will be expanded with basis on the data obtained from other students who attend different programs in the rest of the teacher training institutions in the state of Durango, México. For the achievement of the aforementioned objective, an exploratory, descriptive-correlational, 
transversal and non-experimental study was carried out. Data recollection was done through the ACRA Learning Strategies Scale, which was applied to 67 students who during the month of october 2016 attended the Master's Degree in Education, in the Didactic Intervention Field, at CAM. The main results show that the respondents present an average level of use of Information Coding Strategies (66\%) and that the Gender variable has a modulating effect.

Key words: learning strategies; information coding strategies; teachers; development processes

\section{Introducción}

Este artículo es un reporte parcial de investigación, cuyos resultados representan un insumo fundamental para emprender un Proyecto Educativo orientado a la mejora de los Procesos de Formación Docente que se ofrecen en el estado de Durango, México. Inicialmente se elaborará un diagnóstico sobre las Estrategias de Aprendizaje que emplean los estudiantes, en los diferentes programas educativos de las Instituciones Formadoras de Docentes, con la finalidad de diseñar e implementar posteriormente un Modelo de Formación que aporte a los catedráticos un marco de referencia que les permita adecuar sus estrategias de enseñanza a las características de sus estudiantes, por ende, mejorar su práctica.

Para el caso que nos ocupa, tratando de avanzar en la consecución de lo anterior, en el presente estudio se planteó como objetivo general establecer un perfil descriptivo que contemple las Estrategias de Codificación de Información que emplean los Docentes que estudian la Maestría en Educación, Campo Intervención Didáctica (MECID), en el Centro de Actualización del Magisterio (CAM), para en lo sucesivo ampliarlo con base en los resultados obtenidos con otros estudiantes que cursan distintos programas en el resto de las instituciones en contexto.

Como parte de una gama de Estrategias de Aprendizaje utilizadas por el ser humano, las Estrategias de Codificación de Información refieren al conjunto de procedimientos que conectan los conocimientos previos, integrándolos en estructuras de significado más amplias y transportándolos a la memoria de largo plazo; es decir, a aquellos que transforman y reconstruyen la información, dándole una estructura diferente a fin de comprenderla y recordarla mejor (Pizano, 2012).

\section{Las Estrategias de Aprendizaje como planteamiento teórico general}

Es importante precisar el significado de las Estrategias de Aprendizaje, pues son diversas las definiciones que se han propuesto para abordarlas (Monereo, Castelló, Clariana, Palma y Pérez, 1994). Coincidimos con los autores antes mencionados, respecto a la necesidad de recordar que el término "estrategia" procede del ámbito militar, en el que se entendía como "el arte de proyectar y dirigir grandes movimientos militares" (Gran Enciclopedia Catalana, como se citó en Monereo et al., 1994).

Acorde a lo anterior, la actividad del estratega consistía en proyectar, ordenar y dirigir las operaciones militares, de tal manera que se consiguiera la victoria. También en este entorno militar, los pasos o peldaños que forman una estrategia son llamados "técnicas" o "tácticas".

Monereo et al. (1994) exponen que muchos autores han explicado qué son y qué supone la utilización de estrategias a partir de esta primera distinción entre una técnica -y una estrategia-. 
Las técnicas pueden ser utilizadas de forma más o menos mecánica, sin que sea necesario que para su aplicación exista un propósito de aprendizaje por parte de quien las utiliza; las estrategias, en cambio, son siempre conscientes e intencionales, dirigidas a un objetivo relacionado con el aprendizaje (p. 11).

Esto supone que las técnicas pueden considerarse elementos subordinados a la utilización de estrategias; también los métodos son procedimientos susceptibles de formar parte de una estrategia. Es decir, la estrategia se considera como una guía de las acciones que hay que seguir, y que, obviamente, es anterior a la elección de cualquier otro procedimiento para actuar (Nisbet y Shucksmith, 1986; Schmeck, 1988; Nisbet, 1991; como se citó en Monereo et al., 1994).

En un contexto educativo, las Estrategias de Aprendizaje son procedimientos (conjuntos de pasos, operaciones o habilidades) que un aprendiz emplea en forma consciente, controlada e intencional, como instrumentos flexibles para aprender significativamente y solucionar problemas (Díaz, Castañeda y Lule, 1986; Gaskins y Elliot, 1998; como se citó en Díaz y Hernández, 2002).

Si en el ámbito militar la actividad del estratega consistía en proyectar, ordenar y dirigir las operaciones militares de tal manera que se consiguiera la victoria, Monereo et al. (1994) y Díaz y Hernández (2002), coinciden en que las Estrategias de Aprendizaje, en el ámbito de la educación, son conscientes, controladas e intencionales, dirigidas a un objetivo relacionado con aprender significativamente y resolver problemas, ejecutadas exclusivamente por un aprendiz.

Pozo y Postigo (como se citó en Díaz y Hernández, 2002) indican que son tres los rasgos más característicos de las Estrategias de Aprendizaje:

a) La aplicación de las estrategias es controlada y no automática; requieren necesariamente de una toma de decisiones, de una actividad previa de planificación y de un control de su ejecución. Las Estrategias de Aprendizaje precisan de la aplicación del conocimiento meta cognitivo y, sobre todo, autorregulado.

b) La aplicación experta de las Estrategias de Aprendizaje requiere de una reflexión profunda sobre el modo de emplearlas. Es necesario que se dominen las secuencias de acciones e incluso las técnicas que las constituyen y que se sepa además cómo y cuándo aplicarlas flexiblemente.

c) La aplicación de las mismas implica que el aprendiz las sepa seleccionar inteligentemente de entre varios recursos y capacidades que tenga a su disposición. Se utiliza una actividad estratégica en función de demandas contextuales determinadas y de la consecución de ciertas metas de aprendizaje.

A partir de la revisión de literatura, podemos advertir que hay un consenso entre los autores con relación a que los principales procesos cognitivos de procesamiento de información son los de adquisición, codificación o almacenamiento, recuperación y apoyo; en un marco teórico-conceptual referente a estrategias cognitivas de aprendizaje, estas pueden conceptualizarse de manera genérica como secuencias integradas de procesamiento o actividades 
mentales que se activan (Correa, Castro y Lira, 2004; Nisbett y Shucksmith, 1986; como se citó en Román y Gallego, 2001).

A continuación, se definen los cuatro tipos de Estrategias de Aprendizaje aludidas al principio del párrafo anterior:

a) Estrategias de Adquisición de Información: integra estrategias atencionales y estrategias de repetición; es decir, el primer paso para adquirir información es atender los procesos atencionales, pues son los encargados de seleccionar, transformar y transportar la información desde el ambiente al registro sensorial.

b) Estrategias de Codificación de Información: integra estrategias de nemotecnización, estrategias de elaboración y estrategias de organización; en otras palabras, es la elaboración (superficial o profunda) y la organización más sofisticada de la información, conectan con los conocimientos previos, integrándolos en estructuras de significados más amplios (formas de representación) que constituyen la llamada, por unos, estructura cognitiva y, por otros, base de conocimientos. Codificar, en general, es traducir a un código y/o desde un código. El proceso de codificación se sitúa en la base de los niveles de procesamiento más o menos profundos; de acuerdo con estos, se aproxima más o menos a la comprensión, al significado.

c) Estrategias de Recuperación de Información: estas integran estrategias de búsqueda y estrategias de generación de respuestas de los factores o variables que explican la conducta de un individuo, es la información ya procesada. El sistema cognitivo necesita contar con la capacidad de recuperación o de recuerdo de ese conocimiento almacenado en la memoria de largo de plazo.

d) Estrategias de Apoyo al Procesamiento de la Información: integra estrategias metacognitivas y estrategias socio afectivas. Estas corresponden a las estrategias de apoyo al procesamiento de la información, según Brown (como se citó en Mateos, 2001; Correa, et al., 2004), son habilidades cognitivas necesarias y útiles para la adquisición, uso y control del conocimiento y de otras habilidades similares. Ellas incluyen la habilidad para planificar y regular el uso efectivo de nuestros propios recursos cognitivos. Su importancia radica en que son herramientas necesarias y útiles para darle la efectividad al aprendizaje, y ello es posible porque pueden ser invocadas conscientemente por el lector (y aprendiz, en general) como apoyo para focalizar la atención en los contenidos importantes, en el monitoreo de la comprensión, en determinar propósitos o metas, en lograrlas con éxito y en resolver las dificultades en la comprensión.

\section{Las Estrategias de Codificación de Información como proceso cognitivo}

Las Estrategias de Codificación de Información son el conjunto de procedimientos que conectan los conocimientos previos existentes en la estructura cognitiva de la persona que aprende, con la información nueva que se le presenta, integrando ambos elementos en cuerpos de significado más amplios y transportándolos a la memoria de largo plazo (Pizano, 2012). 
A un nivel cognitivo, partiendo de la propuesta de Cook y Mayer (como se citó en González, Gonzalez-Pienda, Rodríguez, Núñez y Valle, 2005), las Estrategias de Codificación de Información son:

Los propósitos u objetivos del estudio en términos de codificación. La codificación de la información es un proceso interno que supone el manejo de información que nos llega. Los autores proponen un modelo para el análisis de estrategias lectoras donde, entre otros aspectos, listan cuatro tipos generales de procesos de codificación (selección, adquisición, construcción e integración) que consideraron como objetivos de la lectura.

González et al. (2005) establecen que los múltiples propósitos que un aprendiz puede plantearse en su estudio implican tres formas diferentes de enfrentarse a la información y al material de estudio, ejemplifican la importancia del propósito que establece cuando se toman notas en el aula. Sostienen que al tomar notas en una conferencia o en una clase, la intención es anotar el mayor número de ideas posibles para hacer una idea global, ordenando información en forma de guion en el que se pueda observar cómo se relacionan las notas y cuál es la importancia relativa de cada una de ellas.

Rodríguez, González, Valle, García y Rosário (2005) consideran que la toma de nota es una actividad compleja que implica la escucha, el análisis, la síntesis, la selección, la organización, la escritura, y que depende de varios factores. Otro ejemplo que presentan González et al. (2005) concierne al estar interesados en estudiar los argumentos que expone el profesor, debido a que defiende planteamientos que discrepan de los propios, y para ello será necesario traer a la situación de estudio ideas y razonamientos propios en torno al tema; aseveran que al prestar atención y seleccionar los puntos fuertes y débiles, les permite a los estudiantes que su argumentación respecto a la propia opinión la reorganicen si les parece pertinente; esto requiere un planteamiento que lleve a la elaboración de nuevas ideas o pensamientos.

Con los ejemplos anteriores, los autores intentan evidenciar que el tipo de propósitos puede establecerse en un continuum a partir de propósitos más reproductivos (reopinión) (González et al., 2005). Ellos mismos señalan que, en primer lugar, los propósitos se circunscriben a la intención básica de memorizar y reproducir contenidos (los estudiantes toman notas en clase para intentar recoger lo que dice el profesor o para estudiar, hay que repasar información una y otra vez hasta aprenderla).

Un segundo tipo de propósito permitiría al estudiante reconocer cómo se relaciona, cómo se combina o encaja la información, y nuevamente explican cómo los aprendices preparan un guion, donde están ordenadas las ideas importantes; organizar las ideas que formarán parte de los apuntes, haciendo resúmenes, esquemas, cuadros, entre otros, facilita la retención y el recuerdo. Solo la información organizada es significativa y utilizable en el aprendizaje (Shuell, 1986, como se citó en González et al., 2005).

El tercero y último propósito que los estudiantes expresan, es relacionar lo que están estudiando con la vida real. Con base en los principios planteados por John Dewey en su movimiento denominado Escuela Activa, el currículo debe ofrecer al alumno situaciones que lo 
conduzcan a un crecimiento continuo, gracias a la interacción entre las condiciones sociales y personales, entre el entorno físico y social, con las necesidades, intereses, experiencias y conocimientos previos del alumno.

El establecimiento de un propósito de estudio inadecuado, desconocer qué hacer para llegar a aprender y de una manera eficaz, carecer de una base de conocimientos suficiente que le permita tejer redes elaboradas con los conocimientos, abusar de técnicas más complejas o desconocer en qué condiciones es adecuado utilizarlas, sostener motivos o metas personales que no favorezcan la toma de decisiones adecuadas..., pueden ser razones por las que el alumno no sea un "buen estudiante" (Gardner, 1995, como se citó en González et al., 2005).

La realidad es que un número de estudiantes afirma encontrar estas u otras dificultades en el estudio, especialmente entre aquellos que obtienen bajos rendimientos; otro grupo de alumnos manifiesta problemas para desarrollar eficaces estrategias de estudio; es decir, desconocen qué estrategias y técnicas utilizar, y cuándo han de usarlas, no pueden interpretar sus experiencias de estudio de una forma significativa y, por lo tanto, está ausente la metacognición.

Recordemos que la metacognición, de acuerdo con Tobón, Pimienta y García (2010), consiste en:

Orientar a los estudiantes para que reflexionen sobre su desempeño y lo autorregulen (es decir, lo mejoren), con el fin de que puedan realizar un aprendizaje significativo y actúen ante los problemas con todos los recursos personales disponibles. De esta manera, la metacognición no consiste sólo ( $\mathrm{sic}$ ) en tomar conciencia de cómo actuamos, tal como ha sido común entenderla en forma tradicional, sino que implica necesariamente que se dé el cambio, para que pueda considerarse que, en efecto, hay metacognición (p. 81).

Se puede afirmar que los alumnos que logran desarrollar la metacognición en las Estrategias de Aprendizaje que utilizan, son capaces de tomar decisiones que logran asimilar de manera consciente, y aplican estas estrategias en el momento adecuado y de forma correcta. Por ello, la importancia de que los alumnos sean capaces de reflexionar sobre su propio proceso de aprendizaje y logren utilizar estrategias eficaces para aprender permanentemente.

\section{Breve estado del campo de estudio de las Estrategias de Codificación}

En la búsqueda de investigaciones que sirvan como antecedentes del proyecto global, hemos reconocido que, como variables de estudio, las Estrategias de Aprendizaje y las Estrategias de Codificación en particular, han sido abordadas en distintos contextos y en diferentes niveles educativos (Bertel y Martínez, 2012; Cardoso et al., 2013; Norzagaray, Sevillano y Valenzuela, 2012; Ortega, Vázquez y Rosales, 2017; Pelagar-Palomino, 2016).

En un estudio realizado con estudiantes de Ciencias de la Salud en Sucre, Bertel y Martínez (2012) encontraron que el nivel de frecuencia de empleo más bajo es el relacionado con las Estrategias de Codificación (30\% en promedio), le siguen en orden ascendente las de Recuperación (37\%), Apoyo al procesamiento (38\%) y Adquisición (48\%). 
Por otro lado, en México, al medir las estrategias utilizadas por estudiantes de Licenciatura en Administración, Cardoso et al. (2013) encontraron que, en términos de empleo de Estrategias de Codificación entre hombres y mujeres, solamente hay diferencias significativas en las estrategias de elaboración, lo que pudiese suponer una causa del mejor desempeño académico del género femenino. Estos mismos autores subrayan la importancia del desarrollo de Estrategias de Adquisición y Codificación, para alcanzar las de Apoyo al procesamiento de la información.

Algunos investigadores destacan la influencia de elementos contextuales y culturales en el empleo de este tipo de Estrategias de Aprendizaje por parte de los estudiantes (edad, sexo, estilos de aprendizaje, motivación, autorregulación y metas de aprendizaje), así como de la naturaleza del programa educativo que cursan: organización del plan de estudio, estilos de enseñanza del profesorado y métodos instruccionales empleados (Cardoso et al., 2013; Norzagaray, Sevillano y Valenzuela, 2012; Pelagar-Palomino, 2016).

Otros autores sostienen que la apropiación de las Estrategias de Aprendizaje es consecuente con los contextos de enseñanza y no con la complejidad de los contenidos que enfrentan los estudiantes; es decir, afirman que el escenario en el que se opera el programa en cuestión, puede determinar el desarrollo o desvanecimiento de las estrategias (Monereo, Castelló, Clariana y Pérez, 1999, como se citó en Bertel y Martínez, 2012).

Un elemento recurrente en los trabajos de investigación revisados, es el uso de la Escala de Estrategias de Aprendizaje ACRA (Adquisición, Codificación, Recuperación y Apoyo) en la recogida de datos. Este instrumento fue diseñado por José María Román Sánchez y Sagrario Gallego Rico y permite medir el nivel de frecuencia de empleo de uno u otro tipo de Estrategias de Aprendizaje, lo que brinda la posibilidad a investigadores y docentes de aprovechar su utilidad.

Con base en la perspectiva expuesta, se llevó a cabo esta investigación para establecer el nivel de empleo de Estrategias de Codificación de Información por parte de los Docentes que estudian la MECID en el CAM, cuyos objetivos se concretan a continuación:

a) Identificar el nivel de frecuencia de empleo de Estrategias de Codificación de Información en los Estudiantes del Posgrado.

b) Determinar cuáles Estrategias de Codificación de Información tienen un mayor nivel de empleo.

c) Determinar qué Estrategias de Codificación de Información tienen un menor nivel de empleo.

d) Establecer el rol que desempeñan las variables sociodemográficas Género y Semestre que cursa, en el nivel de frecuencia de empleo de Estrategias de Codificación de Información por los Estudiantes del Posgrado. 


\section{Método}

Se realizó un estudio exploratorio, descriptivo-correlacional, transversal y no experimental. Para la recogida de información se utilizó el método de la Encuesta y como instrumento la Escala de Estrategias de Codificación de Información, correspondiente a la segunda sección de la Escala de Estrategias de Aprendizaje ACRA. Los investigadores acudieron personalmente a las aulas para aplicarlo y el proceso se realizó de manera grupal y siguiendo las instrucciones del manual (Román y Gallego, 2001).

\section{Participantes}

El instrumento de medición se aplicó a 67 estudiantes que durante el mes de octubre de 2016 cursaban la MECID en el CAM, el criterio de elegibilidad usado fue que estuvieran cursando el posgrado en la institución; en lo que respecta al sexo de los participantes, 70.1\% fueron mujeres y $29.8 \%$ hombres; el $50.7 \%$ de los estudiantes cursaba primer semestre y el $49.2 \%$ tercer semestre.

\section{Muestreo}

No se realizó muestreo, pues el estudio se llevó a cabo con la población total $(\mathrm{N})$ de estudiantes de posgrado del CAM.

\section{Instrumento}

La Escala de Estrategias de Aprendizaje, conocida también como ACRA (Román y Gallego, 2001), se compone de cuatro escalas independientes, las cuales miden: estrategias de adquisición, de codificación, de recuperación y de apoyo al procesamiento.

De manera particular, la Escala de Estrategias de Codificación de Información (EECI) está compuesta por 46 ítems que abordan procesos de Nemotecnización, Elaboración y Organización, que a su vez contemplan Estrategias de Aprendizaje como Nemotecnias, Relaciones, Imágenes, Agrupamientos, Secuencias, Metáforas, Aplicaciones, Mapas, entre otras (véase Tabla 1).

Ante la pregunta ¿Con qué frecuencia cuando estudio...?, se adecuaron las opciones de respuesta originales, para establecer un escalamiento tipo Lickert de cinco valores, que da cuenta del nivel de empleo de las Estrategias de Aprendizaje incluidas en el instrumento. Así, el encuestado tuvo las siguientes alternativas de respuesta: nunca, casi nunca, algunas veces, casi siempre y siempre.

La Escala de Estrategias de Aprendizaje ACRA presentó una confiabilidad de .96 en alfa de Cronbach en lo general, mientras que la EECI en particular mostró un $\alpha$ de .92 y de .84 en la confiabilidad por mitades, según la fórmula de Spearman-Brown. Estos datos coinciden con los resultados obtenidos en un estudio realizado en estudiantes universitarios del Estado de México, lo cual representa una confiabilidad del proceso de medición alta (Juárez, Pichardo, Escoto y Luna, 2015). 
Tabla 1. Elementos inherentes a la Escala de Estrategias de Codificación de Información.

\begin{tabular}{|c|c|c|c|}
\hline$\frac{\text { Proceso Cognitivo }}{\text { Codificación }}$ & \multicolumn{2}{|c|}{ Estrategias de Aprendizaje } & Tácticas de Codificaci \\
\hline & \multirow[t]{6}{*}{ Nemotecnización } & \multirow[t]{6}{*}{ Nemotecnias } & Acrósticos \\
\hline & & & Acrónimos \\
\hline & & & Rimas \\
\hline & & & Muletillas \\
\hline & & & Loci \\
\hline & & & Palabra-Clave \\
\hline & \multirow[t]{9}{*}{ Elaboración } & \multirow[t]{3}{*}{ Relaciones } & \\
\hline & & & Intracontenido \\
\hline & & & Compartidas \\
\hline & & Imágenes & Imágenes \\
\hline & & Metáforas & Metáforas \\
\hline & & Aplicaciones & Aplicaciones \\
\hline & & Autopreguntas & Autopreguntas \\
\hline & & & Inferencias \\
\hline & & Parafraseado & Parafraseado \\
\hline & \multirow[t]{8}{*}{ Organización } & Agrupamientos & Resúmenes \\
\hline & & & Esquemas \\
\hline & & \multirow[t]{2}{*}{ Secuencias } & Lógicas \\
\hline & & & Temporales \\
\hline & & Mapas & Mapas conceptuales \\
\hline & & Diagramas & Matrices cartesianas \\
\hline & & & Diagramas V \\
\hline & & & Iconografiados \\
\hline
\end{tabular}

Fuente: Elaboración propia, con base en los aportes de Román y Gallego (2001).

\section{Procedimientos de análisis}

Una vez aplicados los instrumentos, se capturaron y procesaron los datos a través del paquete estadístico SPSS (Statistical Package for the Social Sciences), versión 23. Se realizaron las pruebas que se consideraron pertinentes para el logro de los objetivos planteados. Los resultados se comparten en la siguiente sección.

\section{Resultados de la investigación}

El análisis de los resultados se realizó en dos etapas: en la primera, se efectuó el análisis descriptivo abarcando las once Estrategias de Codificación contempladas en el instrumento, a partir de la obtención de las medias aritméticas transformadas posteriormente en porcentajes; en la segunda etapa, se realizó el análisis de diferencia de grupos sin atribución causal, lo que permitió determinar el rol que desempeñan las variables sociodemográficas Género y Semestre que cursa, en el nivel de frecuencia de empleo de las estrategias por parte de los Docentes en el 
Proceso de Formación. Para este análisis se utilizó la prueba estadística $t$ de Student y el análisis de varianza (ANOVA) de un solo factor, siendo la regla de decisión $\mathrm{p}<.05$.

\section{Análisis descriptivo}

La media general obtenida en la aplicación del instrumento Estrategias de Aprendizaje ACRA, particularmente en la Escala de Estrategias de Codificación de Información, fue 3.3. Expresado el dato en términos porcentuales e interpretado a partir de un baremo de tres valores (de 0 a $33 \%$, bajo; de $34 \%$ a $66 \%$, medio; y de $67 \%$ a $100 \%$, alto), podemos afirmar que los Docentes que estudian la Maestría en Educación, Campo Intervención Didáctica (MECID), en el Centro de Actualización del Magisterio (CAM) de Durango, México, presentan un nivel medio de frecuencia de empleo, correspondiente al $66 \%$.

Las Estrategias de Codificación de Información en las que los Docentes presentan un mayor nivel de empleo en el Proceso de Formación de referencia, son las siguientes:

a) Establezco relaciones entre los conocimientos que me proporciona el estudio y las experiencias, sucesos o anécdotas de mi vida particular y social (83\%).

b) Resumo lo más importante de cada uno de los apartados de un tema, lección o apuntes $(83 \%)$.

c) Procuro aprender los temas con mis propias palabras, en vez de memorizar al pie de la letra $(82 \%)$.

A partir de estos resultados, puede observarse que las Estrategias de Aprendizaje que más emplean los Docentes que estudian la MECID en el CAM son: elaboración (imágenes y paráfrasis) y organización (agrupamientos, usando tácticas como resúmenes y esquemas).

Por otra parte, las Estrategias de Codificación de Información en las que los Docentes encuestados presentan un menor nivel de empleo son:

a) Construyo "rimas" o "muletillas" para memorizar listados de términos o conceptos (37\%).

b) A fin de memorizar conjuntos de datos empleo la nemotecnia de los "loci", es decir, sitúo mentalmente los datos en lugares de un espacio muy conocido (40\%).

c) Al estudiar algunas cuestiones (ciencias, matemáticas, etc.) empleo diagramas en V para organizar las cuestiones-clave de un problema, los métodos para resolverlo y las soluciones $(45 \%)$.

Tomando como referencia estos resultados, puede afirmarse que las Estrategias de Aprendizaje que emplean con menor frecuencia los Docentes que estudian la MECID en el CAM, son las siguientes: nemotecnias (acrósticos, acrónimos, rimas, muletillas y Loci) y diagramas (matrices cartesianas, diagramas V e iconografiados). 


\section{Análisis inferencial}

Al llevar a cabo el análisis de diferencia de grupos, se observa que la variable Género establece diferencias significativas en los siguientes ítems:

a) Suelo anotar en los márgenes de lo que estoy estudiando (o en hoja aparte) sugerencias de aplicaciones prácticas que tiene lo leído (sig. 0.00).

b) Para resolver un problema empiezo por anotar con cuidado los datos y después trato de representarlos gráficamente (sig. 0.00).

c) Uso aquello que aprendo, en la medida de lo posible, en mi vida diaria (sig. 0.00).

d) Cuando estudio, hago dibujos, figuras, gráficos o viñetas para representar las relaciones entre ideas fundamentales (sig. 0.00).

e) Busco la "estructura del texto", es decir, las relaciones ya establecidas entre los contenidos del mismo (sig. 0.00).

f) Suelo tomar nota de las ideas del autor en los márgenes del texto que estoy estudiando o en hoja aparte, pero con mis propias palabras (sig. 0.01).

g) Establezco relaciones entre los conocimientos que me proporciona el estudio y las experiencias, sucesos o anécdotas de mi vida particular y social (sig. 0.02).

h) Para elaborar los mapas conceptuales o las redes semánticas, me apoyo en las palabrasclave subrayadas, y en las secuencias lógicas o temporales encontradas al estudiar (0.02).

i) Hago resúmenes de lo estudiado al final de cada tema (sig. 0.03).

j) Aplico lo que aprendo en unas asignaturas para comprender mejor los contenidos de otras (sig. 0.03).

Lo anterior permite afirmar que la variable sociodemográfica Género influye al establecer diferencias significativas en los diez índices empíricos citados, que corresponden preferentemente a las Estrategias de Codificación de elaboración (relaciones, imágenes, aplicaciones, paráfrasis y agrupamiento). Es importante señalar que las mujeres son quienes muestran un mayor nivel de frecuencia de empleo en los ítems planteados.

Con relación a la variable Semestre que cursa, se observa que solamente establece diferencias significativas en el ítem "Al estudiar pongo en juego mi imaginación, tratando de ver como en una película aquello que me sugiere el tema", con un nivel de significación de 0.02. Son los docentes que estudian el tercer semestre de la MECID quienes emplean con mayor frecuencia las Estrategias de Codificación de elaboración, específicamente recurren más a las imágenes como Estrategia de Aprendizaje, respecto a quienes cursan el primer semestre. 


\section{Discusión}

Los resultados obtenidos en el presente estudio son complementarios a los hallazgos en la aplicación de la Escala de Estrategias de Adquisición en la misma población. Contrastando ambas dimensiones del instrumento Estrategias de Aprendizaje ACRA, podemos afirmar que los encuestados emplean preferentemente Estrategias de Adquisición, pues los datos arrojan un nivel alto de frecuencia de empleo (Ortega, Vázquez y Rosales, 2017); mientras que, respecto a las Estrategias de Codificación, se reporta un nivel medio.

Los porcentajes derivados de los estudios realizados al momento (69\% y 66\%, respectivamente) contrastan con el 30\% obtenido por Bertel y Martínez (2012), con relación al nivel de frecuencia de empleo de Estrategias de Codificación por estudiantes universitarios colombianos, lo que hace suponer que la variable Nivel Educativo que cursa es determinante para establecer diferencias significativas. Con base en lo anterior, recobra especial relevancia nuestra intención de complementar el Diagnóstico aplicando los instrumentos a los estudiantes de los programas de licenciatura del CAM.

Pese a que los porcentajes que hemos obtenido son más altos que los que se reportan en otras investigaciones, no podemos perder de vista que incluso el valor más alto está en el límite inferior del nivel en el baremo establecido, y que, además, en ambos resultados hay un margen de mejora amplio respecto a la situación ideal (100\%). Los datos anteriores nos permiten ir ya delineando las estrategias de intervención más adecuadas.

Las Estrategias de Codificación más utilizadas por los estudiantes de posgrado del CAM pertenecen al grupo de Estrategias de Aprendizaje denominadas de Elaboración de la información; en correspondencia a este hallazgo, los catedráticos de la institución que propicien situaciones de aprendizaje orientadas a que los alumnos no solamente elaboren la información que se les brinda, sino que además la organicen usando recursos como las secuencias y mapas conceptuales, tendrán mejores posibilidades de éxito. Esto coincide con lo expuesto por Shuell (como se citó en González et al., 2005), respecto a que solo la información organizada es significativa y utilizable en el aprendizaje.

Las Estrategias de Codificación con menor frecuencia de empleo en los estudiantes de posgrado del CAM son las nemotécnicas, Estrategias de Aprendizaje consistentes en reducir la información recibida a una palabra-clave, $\mathrm{u}$ organizar sus elementos en forma de siglas, rimas o frases. Más allá de la idea de que este tipo de estrategia es un recurso de codificación superficial o elemental, consideramos que su escaso empleo pudiera deberse al desconocimiento de sus bondades, mismas que pueden ser aprovechadas por los catedráticos de la institución para propiciar en los estudiantes el aprendizaje significativo de conceptos.

Con relación a las variables sociodemográficas estudiadas, los hallazgos demuestran que el Género tiene un efecto modulador en las Estrategias de Codificación de Información que emplean los Docentes que estudian la MECID en el CAM, al establecer diferencias significativas en diez ítems del instrumento aplicado. Este dato coincide con lo reportado por Cardoso et al. (2013), quienes midieron la frecuencia de empleo de Estrategias de Codificación de Información 
en estudiantes mexicanos de Licenciatura en Administración, concluyendo que hay diferencias significativas entre hombres y mujeres.

En nuestro estudio, son las mujeres quienes presentan un mayor nivel de frecuencia de empleo de Estrategias de Codificación de Información, resultado que implica al menos dos alternativas de intervención para los catedráticos de la institución: propiciar la mejora de la frecuencia de empleo de este tipo de Estrategias de Aprendizaje en los hombres y diversificar las estrategias de enseñanza para atender las necesidades de todos los integrantes de los diferentes grupos en el Proceso de Formación.

\section{Conclusión}

Los Docentes que estudian la Maestría en Educación, Campo Intervención Didáctica (MECID), en el Centro de Actualización del Magisterio (CAM) de Durango, México, presentan un nivel medio de frecuencia de empleo de Estrategias de Codificación de Información (66\%).

Las Estrategias de Codificación de Información en las que los Docentes presentan un mayor nivel de empleo son: a) Establezco relaciones entre los conocimientos que me proporciona el estudio y las experiencias, sucesos o anécdotas de mi vida particular y social (83\%); b) Resumo lo más importante de cada uno de los apartados de un tema, lección o apuntes $(83 \%)$; y c) Procuro aprender los temas con mis propias palabras, en vez de memorizar al pie de la letra $(82 \%)$.

Las Estrategias de Codificación de Información en las que los encuestados presentan un menor nivel de empleo son: a) Construyo "rimas" o "muletillas" para memorizar listados de términos o conceptos (37\%); b) A fin de memorizar conjuntos de datos empleo la nemotecnia de los "loci", es decir, sitúo mentalmente los datos en lugares de un espacio muy conocido (40\%); y c) Al estudiar algunas cuestiones (ciencias, matemáticas, etc.) empleo diagramas en V para organizar las cuestiones-clave de un problema, los métodos para resolverlo y las soluciones $(45 \%)$.

Por su parte, la variable sociodemográfica Género influye en el nivel de frecuencia de empleo de las Estrategias de Codificación de Información por los Docentes, estableciendo diferencias significativas en diez índices empíricos, teniendo en consecuencia un rol modulador. Son las mujeres quienes presentan un mayor nivel de empleo de Estrategias de Codificación preferentemente de elaboración (relaciones, imágenes, aplicaciones, paráfrasis y agrupamiento).

Este perfil sobre las Estrategias de Codificación de los Docentes que estudian la MECID en el CAM, permite avanzar en la elaboración del Diagnóstico sobre las Estrategias de Aprendizaje empleadas por Estudiantes de distintos programas e instituciones, base fundamental para emprender finalmente un Proyecto Educativo orientado a la mejora de los Procesos de Formación Docente que se ofrecen en el estado de Durango, México.

\section{Bibliografía}


Bertel, P., \& Martínez, J. (2012). Estilos y estrategias de aprendizaje en estudiantes de ciencias de la salud. Psicogente, 15(28), 323-336. Recuperado el 3 de Noviembre de 2016, de http://portal.unisimonbolivar.edu.co:82/rdigital/psicogente/index.php/psicogente

Cardoso, D., Pérez, M., Jaramillo, M., Mendoza, R. V., Santillán, G., \& Bobadilla, S. (2013). Estrategias de Aprendizaje: Efecto en el rendimiento académico por sexo en la licenciatura de administración. Enseñanza e Investigación en psicología, 18(2), 315-328. Recuperado el 04 de Noviembre de 2016, de http://ri.uaemex.mx/handle/20.500.11799/38874

Correa, E., Castro, F., \& Lira, H. (2004). Estudio descriptivo de las estrategias cognitivas y metacognitivas de los alumnos y alumnas de primer año de pedagogía en enseñanza media de la Universidad de Bío-Bío. Theoria. Ciencia, arte y humanidades, 13(1), 103-110. Recuperado el 5 de octubre de 2017, de http://www.redalyc.org/articulo.oa?id=29901310

Díaz, F., \& Hernández, G. (2002). Estrategias docentes para un aprendizaje significativo. Una interpretación constructivista (2da ed.). (F. Hernández Carrasco, Ed.) Ciudad de México, México: Mc Graw Hill Interamericana. Recuperado el 26 de abril de 2017, de http://memsupn.weebly.com/uploads/6/0/0/7/60077005/estrategias_docentes_para_un_ap je._significativo-frida_d\%C3\%8Daz_barriga_parte_1_de_4.pdf

González, R., González, J., Rodríguez, S., Núñez, J., \& Valle, A. (2005). Estrategias y técnicas de estudio. Madrid, España: Pearson Educación.

Juárez, C. S., Pichardo, K., Escoto, M. C., \& Luna, E. L. (2015). Confiabilidad y validez de la escala de Estrategias de aprendizaje ACRA en estudiantes del Estado de México. (P. Palacios, Ed.) Investigación y Práctica en Psicología del Desarrollo, 1(1), 261-268. Recuperado el 27 de Octubre de 2016, de http://ri.uaemex.mx/handle/20.500.11799/32743

Mateos, M. (2001). Metacognición y educación. Buenos Aires, Argentina: Editorial Aique.

Monereo, C., Castelló, M., Clariana, M., Palma, M., \& Pérez, M. (1994). Estrategias de enseñanza y aprendizaje. Barcelona, España: Grao.

Norzagaray, C. C., Sevillano, M. L., \& Valenzuela, B. A. (2012). Estrategias de Aprendizaje en estudiantes de psicología. European Scientific Journal, 8(28), 102-119. Recuperado el 05 de Noviembre de 2016, de http://www.eujournal.org/index.php/esj/article/view/641

Ortega, F., Vázquez, D., \& Rosales, R. (2017). Estrategias de Adquisición de Información empleadas por Estudiantes de Posgrado en Durango. Memoria del XIV Congreso Nacional de Investigación Educativa COMIE.

Pelagar-Palomino, M. (2016). Estrategias de aprendizaje en alumnado universitario para la formación presencial y semipresencial. Revista Latinoamericana de Ciencias Sociales, Niñez y Juventud, 1(14), 659-676. DOI:10.11600/1692715x.14145071114 
Pizano, G. (2012). Las estrategias de aprendizaje. Un avance para lograr el adecuado procesamiento de la información. Investigación Educativa, 16(29), 57-68. Recuperado el 4 de Noviembre de 2016, de http://sisbib.unmsm.edu.pe/bibvirtual/publicaciones/inv_educativa/2012_n29/pdf/a05v16 n29.pdf

Rodríguez, S., González, R., Valle, A., Gracia, M., \& Rosário, P. (2005). La toma de notas en el aula. En Estrategias y técnicas de estudio: cómo aprender a estudiar estratégicamente. Madrid, España: Pearson Educación.

Román, J. M., \& Gallego, S. (2001). ACRA. Escalas de Estrategias de Aprendizaje (3 ed.). Madrid, España: Publicaciones de Psicología Aplicada.

Tobón, S., Pimienta, J., \& García, J. (2010). Secuencias didácticas: aprendizaje y evaluación por competencias. Ciudad de México, México: Pearson Educación. 